\title{
Synapsin Utilization Differs among Functional Classes of Synapses on Thalamocortical Cells
}

\author{
Anders Kielland, ${ }^{1}$ Alev Erisir, ${ }^{2}$ S. Ivar Walaas, ${ }^{1}$ and Paul Heggelund ${ }^{1}$ \\ ${ }^{1}$ University of Oslo, Institute of Basic Medical Sciences, N-0317 Oslo, Norway, and 2University of Virginia, Department of Psychology, Charlottesville, \\ Virginia 22904-4400
}

\begin{abstract}
Several proteins in nerve terminals participate in synaptic transmission between neurons. The synapsins, which are synaptic vesicleassociated proteins, have widespread distribution in the brain and are assumed essential for sustained recruitment of vesicles during high rates of synaptic transmission. We compared the role of synapsins in two types of glutamatergic synapses on thalamocortical cells in the dorsal lateral geniculate nucleus of mice: retinogeniculate synapses, which transmit primary afferent input at high frequencies and show synaptic depression, and corticogeniculate synapses, which provide modulatory feedback at lower frequencies and show synaptic facilitation. We used electrophysiological methods to determine effects of gene knock-out of synapsin I and II on short-term synaptic plasticity in paired-pulse, pulse-train, and posttetanic potentiation paradigms. The gene inactivation changed the plasticity properties in corticogeniculate, but not in retinogeniculate, synapses. Immunostaining with antibodies against synapsins in wild-type mice demonstrated that neither synapsin I nor II occurred in retinogeniculate terminals, whereas both occurred in corticogeniculate terminals. In GABAergic terminals, only synapsin I occurred. In corticogeniculate terminals of knock-out mice, the density of synaptic vesicles was reduced because of increased terminal size rather than reduced number of vesicles and the intervesicle distance was increased compared with wild-type mice. In the retinogeniculate terminals, no significant morphometric differences occurred between knock-out and wildtype mice. Together, this indicates that synapsin I and II are not present in the retinogeniculate terminals and therefore are not essential for sustained, high-rate synaptic transmission.
\end{abstract}

Key words: synaptic transmission; synapsin; facilitation; depression; PTP; synaptic terminals; synaptic vesicle clusters; thalamus; LGN

\section{Introduction}

The synapsins constitute a neuronal protein family encoded by three genes, synapsin I, II, and III, which are expressed in different splice variants (Südhof et al., 1989; Hosaka and Südhof, 1998; Kao et al., 1998; Ferreira et al., 2000). Synapsins are localized in nerve terminals and are the most abundant synaptic vesicleassociated proteins in the adult vertebrate brain. They appear to tether vesicles to each other and to the cytoskeleton, thereby maintaining a reserve pool of synaptic vesicles in the nerve terminals (De Camilli et al., 1990; Walaas and Greengard, 1991; Greengard et al., 1993). The dynamics of the reserve pool, and thus the mobilization of vesicles for synaptic release, may be regulated through several phosphorylation sites present on synapsins (De Camilli et al., 1990; Walaas and Greengard, 1991; Greengard et al., 1993; Hosaka et al., 1999; Jovanovic et al., 2001;

\footnotetext{
Received 0ct. 28, 2005; revised March 2, 2006; accepted April 19, 2006.

The project was financially supported by the Molecular Neurobiology Research Group (University of 0slo, Oslo, Norway) and the Norwegian Research Council. The mutated and control mice were gifts from Dr. Paul Greengard (Rockefeller University, New York, NY) and Dr. Hung-Teh Kao (Nathan Kline Institute for Psychiatric Research, Orangeburg, NY). We thank Dr. Barry Condron (University of Virginia, Charlottesville, VA) for methodological assistance with calculations of intervesicle distances, Basak Gonen (University of Virginia, Charlottesville, VA) for the vesicle coordinate plotting, and Inger Lise Bogen (University of Oslo, Oslo, Norway) for help with Western blotting

Correspondence should be addressed to Paul Heggelund, Department of Physiology, University of 0slo, Institute of Basic Medical Sciences, P.0. Box 1103 Blindern, Sognsvannsveien 9, N-0317 Oslo, Norway. E-mail: paul.heggelund@medisin.uio.no.

D0I:10.1523/JNEUROSCI.4631-05.2006

Copyright $\odot 2006$ Society for Neuroscience $\quad$ 0270-6474/06/265786-08\$15.00/0
}

Chi et al., 2003). The state of synapsin phosphorylation is dependent on the activity in the synapse, indicating that synapsins perform a modulatory role in relation to the rate of synaptic transmission (Jovanovic et al., 2001; Chi et al., 2003).

Selective depletion of the synapsin-associated pool of vesicles in terminals of lamprey or squid axons by injection of synapsin antibodies or competitive peptides led to enhanced depression of synaptic transmission at high-frequency stimulation but not at low-frequency stimulation (Pieribone et al., 1995; Hilfiker et al., 1998 , 2005). Corresponding findings were reported after inactivation of the genes encoding either synapsin I and II (Rosahl et al., 1995) or synapsin I, II, and III (Gitler et al., 2004). These results led to the view that synapsins are required for establishing a reserve pool of vesicles, which can provide efficient recruitment of vesicles to the active zone and thereby maintain release of neurotransmitter during high rates of synaptic transmission (Hilfiker et al., 1999).

To examine the validity of this hypothesis, we studied synaptic transmission at two types of glutamatergic synapses on thalamocortical cells in the dorsal lateral geniculate nucleus (LGN) that have different properties of transmission: retinogeniculate synapses that show depression (Turner and Salt, 1998; Chen et al., 2002; Kielland and Heggelund, 2002) and transmit primary afferent signals at high frequency (Creutzfeldt et al., 1970) and corticogeniculate synapses that show facilitation (Wrobel and Lindström, 1990; Turner and Salt, 1998; von Krosigk et al., 1999; 
Granseth et al., 2002) and transmit feedback signals at lower rates (Tsumoto et al., 1978). We found that synapsin I and II are not used in the transmission at the retinogeniculate synapses but that both synapsin I and II are used in the transmission at the corticogeniculate synapses. Accordingly, synapsin I and II are not necessary for the high-rate transmission that occur at the primary afferent input to the thalamocortical cells. However, the synapsins appear to be important for the lower-rate transmission at inputs that have a modulatory function on the firing pattern in thalamocortical cells.

\section{Materials and Methods}

Electrophysiology. Mice with double knock-out mutation of the synapsin I and II genes and wild-type mice with the same genetic background were used in this study. Animals were prepared according to the guidelines and with the approval of the Animal Care Committee in Norway. Animals, 17-20 d old, were killed by rapid decapitation. A block of the brain containing the thalamus was dissected out and cooled to below $5^{\circ} \mathrm{C}$ in artificial CSF (ACSF) containing the following (in mM): $125 \mathrm{NaCl}, 2.5$ $\mathrm{KCl}, 2 \mathrm{CaCl}_{2}, 1 \mathrm{MgCl}_{2}, 25 \mathrm{NaHCO}_{3}, 1.25 \mathrm{NaH}_{2} \mathrm{PO}_{4}$, and 25 D-glucose (bubbled with $5 \% \mathrm{CO}_{2} / 95 \% \mathrm{O}_{2}$ ). Brain slices of LGN were cut from the block at a thickness of $250 \mu \mathrm{m}$, in a semi-parasagittal plane as described previously (Turner and Salt, 1998), using a vibroslicer (Sigmann Electronics, Hüffenhardt, Germany). The slices were stored submerged in ACSF at room temperature $\left(\sim 24^{\circ} \mathrm{C}\right)$ until recording and were used for recording within $5 \mathrm{~h}$.

During experiments, slices were kept submerged in a small chamber (volume, $\sim 1.5 \mathrm{ml}$ ). The chamber was perfused with ACSF at the rate of 3 $\mathrm{ml} / \mathrm{min}$ at a temperature of $28 \pm 1^{\circ} \mathrm{C}$. Picrotoxin (80-100 $\mu \mathrm{M}$; SigmaAldrich, St. Louis, MO) was added to the perfusion solution to block $\mathrm{GABA}_{\mathrm{A}}$-receptor-mediated synaptic currents, and $50 \mu \mathrm{M}$ D-APV (Tocris Cookson, Avonmouth, UK) was added during experiments with train stimulus protocols to prevent induction of NMDA-receptor-mediated forms of synaptic plasticity. Cells were visualized with differential interference contrast using infrared light. Whole-cell voltage-clamp recordings were obtained with glass electrodes filled with the following (in $\mathrm{mM}$ ): $80 \mathrm{Cs}_{2} \mathrm{SO}_{4}, 8 \mathrm{NaCl}, 0.5 \mathrm{MgCl}_{2}, 0.5 \mathrm{CaCl}_{2}, 3 \mathrm{Na}_{2} \mathrm{ATP}, 10 \mathrm{HEPES}, 5$ EGTA, and $0.1 \mathrm{D}-600$ (blocks L-type $\mathrm{Ca}^{2+}$ channels; Sigma-Aldrich). The $\mathrm{pH}$ was adjusted to 7.2 with $\mathrm{CsOH}$. $\mathrm{Cs}_{2} \mathrm{SO}_{4}$ was added to block $\mathrm{GABA}_{\mathrm{B}}$ currents and to make the cells electronically more compact by blocking $\mathrm{K}^{+}$channels. The access resistance $(11 \pm 3 \mathrm{M} \Omega)$ was continuously monitored during the experiments, and it varied $<15 \%$ during an experimental series. A maximum of three recordings were done in each slice. Postsynaptic currents were evoked by electrical stimulation of the retinogeniculate and corticogeniculate fibers with bipolar electrodes, using 100 - to 300- $\mu$ s-long current pulses of 5-100 $\mu \mathrm{A}$ (Turner and Salt, 1998). The stimulus artifacts are truncated in the figures. The recorded electrical signals were low-pass filtered at $3 \mathrm{kHz}$ and sampled at $10 \mathrm{kHz}$ with a Multiclamp 700A amplifier and pClamp software (Molecular Devices, Palo Alto, CA). The amplitude of the postsynaptic currents was calculated as the difference between the peak synaptic current and the baseline holding current or the decaying current of a preceding synaptic event. Off-line analysis was done with Igor Pro (WaveMetrics, Lake Oswego, OR) in combination with the NeuroMatic tool packet (ThinkRandom) and custom-made functions.

Morphology. The mice were anesthetized with Nembutal, perfused transcardially for 2 min with ACSF, and subsequently for 20 min with a fixating solution containing $4 \%$ paraformaldehyde and $1 \%$ glutaraldehyde dissolved in $0.1 \mathrm{~m}$ phosphate buffer at $\mathrm{pH}$ 7.4. A block of the brain was dissected out and postfixed for 2-3 h. The LGN was cut in coronal sections of $100 \mu \mathrm{m}$ using a vibroslicer (Sigmann Electronics). The sections were treated with $1 \% \mathrm{NaBH}_{4}$ to terminate the cross-linking actions of the fixatives and stored at $4^{\circ} \mathrm{C}$ in PBS (0.01 M phosphate buffer and 9\% $\mathrm{NaCl}, \mathrm{pH} 7.4$ ), including $0.05 \%$ sodium azide to prevent microbial growth.

For immunocytochemistry, the following primary antibodies were used: polyclonal goat anti-synapsin Iab (1:100 dilutions; Santa Cruz Biotechnology, Santa Cruz, CA), and rabbit anti-synapsin IIab $(0.1 \mu \mathrm{g} / \mathrm{ml}$;
StressGen Biotechnologies, Victoria, British Columbia, Canada). Before antibody incubation, the sections were rinsed in PBS and treated in 1\% bovine serum albumin (BSA) dissolved in PBS for $30 \mathrm{~min}$. The primary antibodies, the specificity of which had been confirmed by Western blotting of total brain extracts (data not shown), were diluted in PBS with $1 \%$ BSA and $0.05 \%$ sodium azide. The incubation lasted for $3 \mathrm{~d}$ at room temperature. Sections were rinsed in PBS and incubated for $2 \mathrm{~h}$ in biotinylated anti-goat or anti-rabbit secondary antibody (1:100, in PBS; Vector Laboratories, Burlingame, CA), followed by $2 \mathrm{~h}$ in HRPconjugated avidin-biotin complex (ABC; Vector Laboratories). Immunoreactivity was visualized using $0.05 \%$ diaminobenzidine and $0.001 \%$ $\mathrm{H}_{2} \mathrm{O}_{2}$. For all antibodies, deletion of the primary antibody in the protocol eliminated the specific staining discernible at the electron microscopic level.

Immunostained sections were fixed with $1 \% \mathrm{OsO}_{4}$ for $1 \mathrm{~h}$. The sections were briefly immersed in 50\% ethanol, incubated in $4 \%$ uranyl acetate diluted in $50 \%$ ethanol for $1 \mathrm{~h}$, and finally dehydrated in a series of ethanol. The sections were rinsed in acetone and saturated with Epon (Electron Microscopy Sciences, Fort Washington, PA) by first incubating them in equal amount of acetone and Epon and next in pure EPON. The sections were flat embedded between two pieces of Aclar sheet (Ted Pella, Redding, CA). The areas to be analyzed by electron microscopy were identified using camera lucida, encapsulated with Epon, and polymerized at $60^{\circ} \mathrm{C}$ for $2 \mathrm{~d}$. Ultrathin sections of $80 \mathrm{~nm}$ were cut using an ultra microtome (Ultracut UC7; Leica, Nussloch, Germany). The cutting angle was oriented near parallel to the surface of the embedded tissue to maximize the area of the tissue-Epon interface within the sections. This approach permitted the most efficient detection of immunolabeled profiles because antibody penetration is limited to the surface layer of the tissue.

Ultrathin sections were examined in an electron microscope (JEOL1010; Japan Electron Optic, Tokyo, Japan), and micrographs of regions with labeling were taken at $12,000-15,000 \times$ magnification. The negatives were scanned to digitize at 600 dots per inch (dpi) and examined at a final magnification of at least $60,000 \times$ using Image-Pro Plus 4.0 (Media Cybernetics, Silver Spring, MD). Additional photographs were captured using a 16 megapixel digital camera (SIA) at 10,000-15,000 $\times$ magnifications. Retinal (RL), presumed cortical (RS), and inhibitory (F) terminals were identified by their specific morphology (Steriade et al., 1997). For vesicle density analysis, the cross-section area of each terminal (excluding the area occupied by mitochondrion or membrane-limited inclusions typically encountered in RL terminals) was measured using Image-Pro Plus, and the vesicles contained within the terminal were counted. To compute intervesicle distances, we determined the $x-y$ coordinates of each vesicle within each terminal and calculated the intervesicle distances from these coordinate values. Using a spreadsheet algorithm, designed by Dr. Barry Condron (University of Virginia, Charlottesville, VA), we computed the intervesicle distances between every possible vesicle pairs within each terminal and extracted the shortest distance obtained for each vesicle. Pictures for illustrations were prepared by scanning the negatives at 2400 dpi to compose enlarged images at 400 dpi.

Statistical analyses. Tests of statistical significance were done using $t$ test or ANOVA with Bonferroni's correction (SSPS software; SPSS, Chicago, IL).

\section{Results}

\section{Electrophysiology}

We used whole-cell voltage-clamp technique to record EPSCs evoked in thalamocortical cells by electrical stimulation of afferents from retina and visual cortex and compared transmission properties in synapsin I and II double knock-out mice with those in wild-type mice.

Single-pulse stimulations of optic tract fibers in the wild-type mice gave EPSCs in thalamocortical cells $(n=20)$ that had an average \pm SEM amplitude of $-862 \pm 153 \mathrm{pA}$, a rise time (10$90 \%)$ of $0.48 \pm 0.009 \mathrm{~ms}$, and a decay time constant of $1.43 \pm$ $0.007 \mathrm{~ms}$. For cells $(n=20)$ in the double knock-out mice, the 


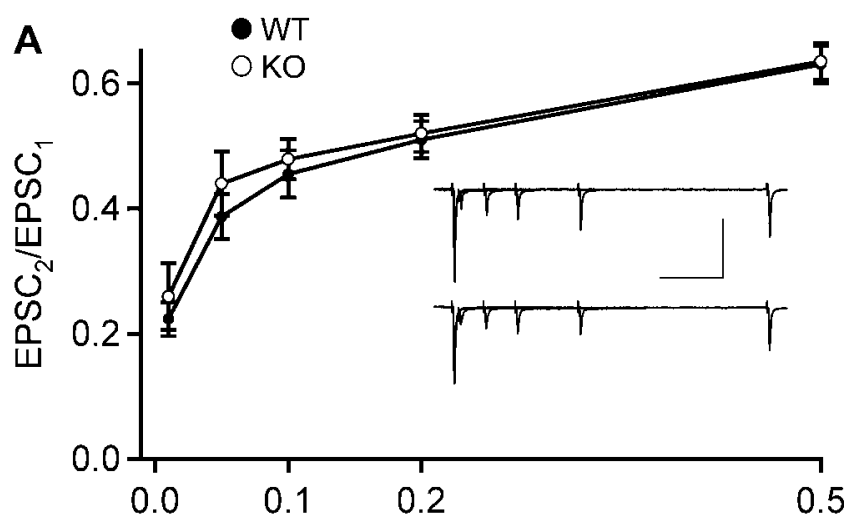

B

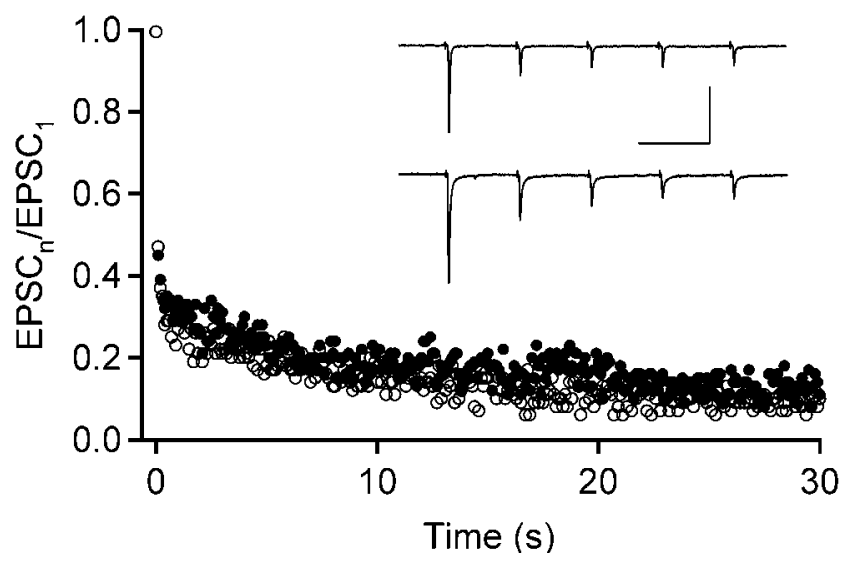

Figure 1. Synapsin double knock-out mice and wild-type mice had similar characteristics of short-term depression in retinogeniculate synapses. $\boldsymbol{A}$, Responses evoked by paired-pulse stimulation of retinal afferents in wild-type (WT) and double knock-out (KO) mice. Summated data from all recordings are shown. Error bars indicate SEM. The inset shows examples of five superimposed traces with different interstimulus intervals. Top traces, Wild-type mouse; bottom traces, synapsin I and II double knock-out mouse. $\boldsymbol{B}$, Responses to pulse-train stimulation with 300 pulses delivered at $10 \mathrm{~Hz}$. Summated data from all recordings. The inset shows examples of responses to the first five pulses in the train from a cell of a wild-type mouse (top trace) and a synapsin I and II double knock-out mouse (bottom trace). Calibration: 100 ms, 500 pA.

corresponding EPSCs had a mean \pm SEM amplitude of $-829 \pm$ $213 \mathrm{pA}$, a rise time of $0.48 \pm 0.015 \mathrm{~ms}$, and a decay time constant of $1.45 \pm 0.010 \mathrm{~ms}$. We found no statistically significant difference between the two genotypes for any of these parameters (range of $p$ values, $0.32-0.62$ ). Single-pulse stimulations of cortical afferents in the wild-type mice elicited EPSCs in thalamocortical cells $(n=15)$ that had an average \pm SEM amplitude of $-48.4 \pm 5.7 \mathrm{pA}$, a rise time of $1.62 \pm 0.024 \mathrm{~ms}$, and a decay time constant of $2.64 \pm 0.052 \mathrm{~ms}$. For cells $(n=14)$ in the double knock-out mice, the average \pm SEM EPSC had an amplitude of $-52.2 \pm 9.3 \mathrm{pA}$, a rise time of $1.60 \pm 0.027 \mathrm{~ms}$, and a decay time constant of $2.57 \pm 0.044 \mathrm{~ms}$. For neither of these parameters did we observe any statistically significant differences between the wild-type and the double knock-out mice (range of $p$ values, 0.85-0.89).

Repetitive stimulation of retinal afferents in normal rats and mice gives synaptic depression in thalamocortical cells (Turner and Salt, 1998; Chen et al., 2002; Kielland and Heggelund, 2002). We used both paired-pulse stimulation with interpulse intervals in the range 10-500 $\mathrm{ms}$ (Fig. $1 A$ ) and pulse-train stimulation with 300 pulses delivered at $10 \mathrm{~Hz}$ (Fig. $1 \mathrm{~B}$ ) and found synaptic depression in both double knock-out and wild-type mice with both types of stimuli. Interestingly, there was no statistically significant difference between the degrees of depression in the two genotypes (range of $p$ values, $0.22-0.24$ ).

We also tested whether there was any difference in posttetanic potentiation (PTP) at the retinogeniculate synapses between the two types of mice using a tetanic stimulus of 100 pulses delivered at $100 \mathrm{~Hz}$. A possible potentiation was examined by evoking EPSCs at a frequency of $0.1 \mathrm{~Hz}$ for a period of $2.5 \mathrm{~min}$ after the tetanic stimulation. For both wild-type and double knock-out mice, the size of the EPSCs did not increase after the tetanic stimulation. Accordingly, at the retinogeniculate synapse, PTP was present in neither the wild-type nor the double knock-out mice (data not shown). In summary, these data indicate that gene inactivation of synapsin I and II have no effects on short-term plasticity in the retinogeniculate synapses.

Repetitive stimulation of corticogeniculate afferents in normal animals gives synaptic facilitation in thalamocortical cells (Wrobel and Lindström, 1990; Turner and Salt, 1998; von Krosigk et al., 1999). We found such facilitation in both double knock-out and wild-type mice. However, the strength of the facilitation differed between the two genotypes. Paired-pulse effects were studied with interpulse intervals in the range of 10-500 $\mathrm{ms}$, as in the studies of the retinal input. In the wild-type mice, we found that the facilitation was most pronounced at the shortest interpulse interval with gradually less facilitation during prolongation of the intervals (Fig. $2 \mathrm{~A}$, filled spots). The time course did not show a simple exponential pattern, which suggests that different biological processes are involved (Granseth et al., 2002). In the double knock-out mice, the paired-pulse facilitation at the corticogeniculate synapse showed similar time course as in the wild-type mice, but the facilitation was considerably stronger in the double knock-out mice (Fig. $2 \mathrm{~A}$, open spots). The facilitation was $\sim 50 \%$ stronger at intervals in the range of $10-100 \mathrm{~ms}$. At all of the interpulse intervals from 10 to $200 \mathrm{~ms}$, there was significant differences between the two genotypes $(p<0.005)$, but, for the 200 and $500 \mathrm{~ms}$ interpulse intervals, the differences were not statistically significant.

Stimulation of the corticogeniculate fibers in wild-type mice with a train of 300 shocks at $10 \mathrm{~Hz}$ gave a large increase in the amplitude of the first EPSCs (Fig. 2B). The EPSCs continued to increase but less pronounced for the next 50-70 responses. Thereafter, the EPSCs gradually declined in size (Fig. $2 B$, filled spots). The synaptic responses reached maximal amplitudes after $\sim 5 \mathrm{~s}$ with EPSCs that were $\sim 2.7$ times larger than the EPSCs recorded before the start of train stimulation. At the end of the train, the amplitudes of the EPSCs were $\sim 1.5$ times larger than the pre-train responses. In the double knock-out mice, the same type of train stimulation gave a large increase in the amplitude of the second EPSC of the train. However, immediately thereafter, the synaptic responses began to decrease (Fig. $2 \mathrm{~B}$ ). Relative to the pre-train responses, there was an average increase of amplitude by a factor of 3.1 at the second EPSC, 2.5 at the third EPSC, and 2.2 at the fourth EPSC. For the rest of the train period, the EPSCs declined with a near-linear time course and reached pre-train level after $\sim 25 \mathrm{~s}$ (Fig. 2 B, open spots). The difference obtained between the wild-type and the double knock-out mice in the pattern of EPSCs during train stimulation was statistically significant $(p=0.019)$.

The difference between the two genotypes revealed during train stimulation suggests that the deletion of synapsin I and II can affect other types of synaptic plasticity besides facilitation. We therefore also tested for a difference with respect to PTP using 

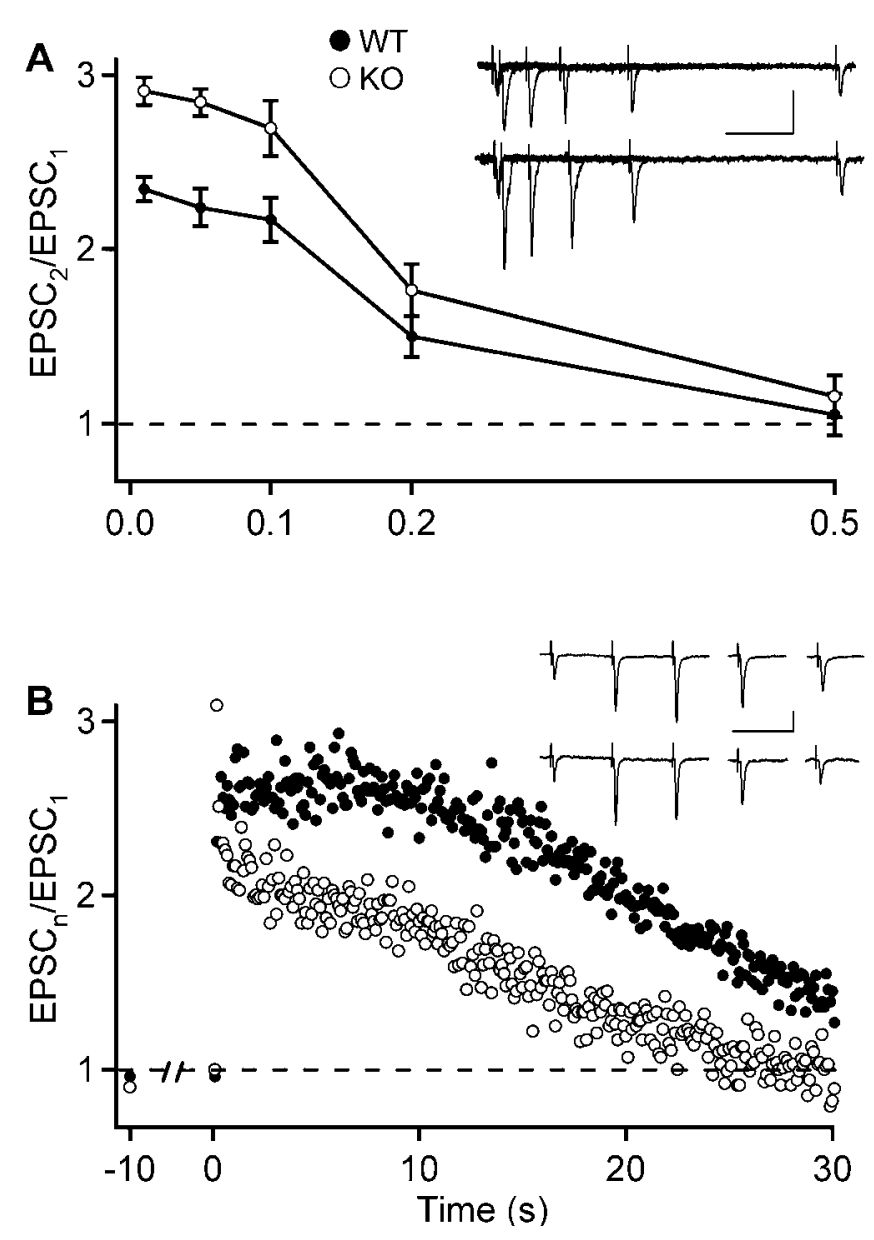

Figure 2. Synapsin double knock-out (KO) mice and wild-type (WT) mice had different characteristics of short-term facilitation in corticogeniculate synapses. $A$, Responses to pairedpulse stimulation of cortical afferents. Summated data from all recordings are shown. Error bars indicate SEM. The inset shows examples of five superimposed traces with different interstimulus intervals. Top traces, Wild-type mouse; bottom traces, synapsin I and II double knock-out mouse. $\boldsymbol{B}$, Responses to pulse-train stimulation with 300 pulses at $10 \mathrm{~Hz}$. Sum of data from all recordings. The inset shows the first three EPSCS, the 50th EPSC, and the last EPSC of single traces from a wild-type mouse (top trace) and a synapsin I and II double knock-out mouse (bottom trace). Calibration: $100 \mathrm{~ms}, 50 \mathrm{pA}$.

the same stimulus protocol as used in the studies of the retinal input, i.e., 100 shocks at $100 \mathrm{~Hz}$ followed by test stimuli at a frequency of $0.1 \mathrm{~Hz}$ for $2.5 \mathrm{~min}$ (Fig. 3). In the wild-type mice, the mean amplitude of the EPSC at the first test stimulus increased by a factor of 3.9 relative to the pretetanic EPSCs (Fig. 3, filled spots). The test responses declined thereafter, with a time constant of 19.2 s. At the end of our recording period, the average EPSC was still 1.45 times the pre-train level. This demonstrated the presence of PTP at the corticogeniculate synapses in the normal mice. The double knock-out mice also showed PTP at corticogeniculate synapses, but the potentiation was significantly weaker $(p=$ 0.003 ) (Fig. 3, open spots). At the first test stimulation, $10 \mathrm{~s}$ after the end of the tetanic stimulation, the amplitude of the mean EPSC had increased by a factor of 2.1 relative to the pretetanic EPSCs. The responses declined gradually with a time constant of $27.3 \mathrm{~s}$, and reached pre-tetanic level after $\sim 1.5 \mathrm{~min}$. Thus, in the late stage of the $10 \mathrm{~Hz}$ train and after the induction of PTP, we found weaker synaptic responses in the double knock-out mice compared with the wild-type mice at the corticogeniculate synapse, and these results are consistent with a putative role of syn-

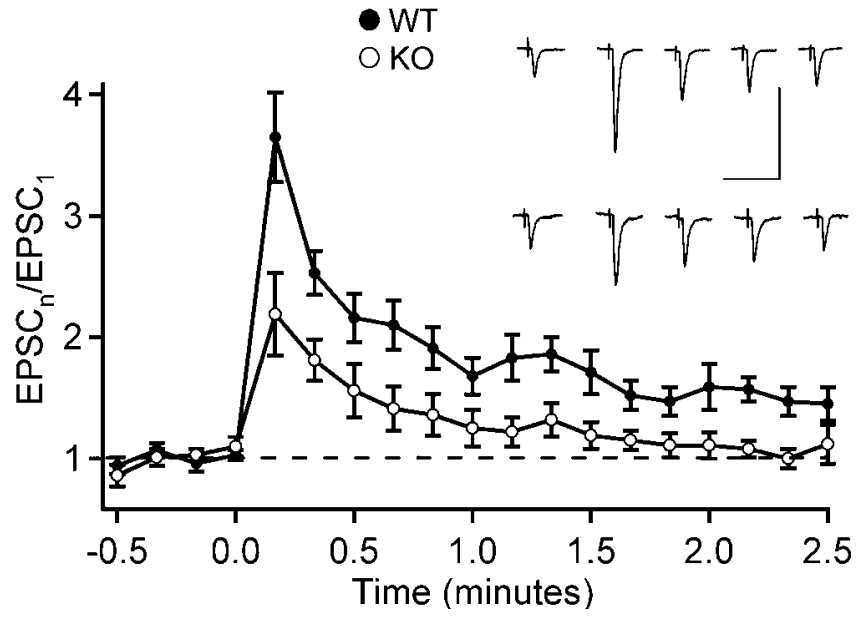

Figure 3. Posttetanic potentiation occurred at corticogeniculate synapses but was less pronounced in double knock-out (KO) mice compared with wild-type (WT) mice. Responses evoked by test pulses delivered at 10 s intervals before and after application of a tetanic stimulus (100 pulses at $100 \mathrm{~Hz}$ ). Summated data from all recordings are shown. Error bars indicate SEM. The inset shows examples of single EPSCs (before, 10,30,90, and 150 s after tetanization) from a cell of a wild-type mouse (top trace) and a synapsin I and II double knock-out mouse (bottom trace). Calibration: $500 \mathrm{~ms}, 500 \mathrm{pA}$.

apsins in the regulation of availability of vesicles for the transmitter release process (Greengard et al., 1993; Hosaka et al., 1999).

\section{Morphology}

The physiological differences in synaptic plasticity between the double knock-out and the wild-type mice at the corticogeniculate synapses, together with the lack of differences at the retinogeniculate synapses, suggested differential utilization of synapsins at the two types of synapses. To analyze this further, we studied the distribution of synapsin I and II in the two types of terminals in wild-type mice using immunohistochemical labeling and electron microscopy. Retinal and cortical terminals can be distinguished at the ultrastructural level because of their characteristic appearance (Steriade et al., 1997). Retinal terminals have round vesicles, are large (RL terminals), contain pale mitochondria, and form asymmetric synapses. Cortical terminals have round vesicles but are small (RS terminals), contain no or a few dark-appearing mitochondria, and form asymmetric synapses. Terminals from inhibitory neurons have flattened vesicles ( $\mathrm{F}$ terminals), dark mitochondria, and form symmetrical synapses.

We stained sections of LGN from the wild-type mice with antibodies specific for either synapsin Ia and Ib or synapsin IIa and IIb. Every micrograph used in our immunohistochemical analysis had at least several labeled profiles, confirming that antibody penetration did occur in the actual regions. Immunostaining of the double knock-out mice confirmed the specificity of the antibodies because sections from these animals were devoid of labeling for either type of antibody.

Labeling with antibodies toward synapsin I was examined in 44 micrographs from three mice, and all terminals in the micrographs were classified as far as possible. Within these micrographs, we encountered 89 labeled profiles of 209 recognized terminals. Labeling was found in 53 RS terminals (Fig. 4A,D) and $36 \mathrm{~F}$ terminals (Fig. $4 B, D$ ), whereas no labeling was found in $\mathrm{RL}$ terminals (Fig. 4D).

Labeling with antibodies toward synapsin II was examined in 32 micrographs from two mice. Within these micrographs, we encountered 64 labeled profiles of 171 recognized terminals. All 
of the labeled terminals were of the RS variety (Fig. $4 C, D$ ). Finally, the overall distribution of the different terminals, labeled and unlabeled, were 8,60 , and $32 \%$ for the RL, RS, and F types, respectively (Fig. 4D). These percentages are consistent with the expected distribution of input terminals in mice LGN based on what was described previously in detailed quantitative studies in cat (Montero, 1991; Erisir et al., 1998), confirming the validity of our identification criteria.

The lack of labeling of RL terminals could potentially be attributable to unsuccessful antibody penetration of these terminals. However, the simultaneous lack of staining of the RL terminals and positive staining of the RS terminals with antibodies against synapsin I and synapsin II observed in the same sections argues against this explanation. Moreover, the immunohistochemical data are consistent with our electrophysiological data.

Because synapsins presumably tether vesicles in the terminals, knock-out of the synapsins would be expected to reduce the density of vesicles (Rosahl et al., 1995; Takei et al., 1995; Gitler et al., 2004; Samigullin et al., 2004) and increase the distance between vesicles in the terminals. We studied these parameters to look for morphological changes induced by synapsin I and II gene inactivation. Qualitatively, we saw no pronounced differences in the density of vesicles between terminals from wild-type and double knock-out mice (Fig. 5A-C). However, careful quantitative analysis revealed significant differences for the RS terminals but not for the RL terminals, consistent with a differential
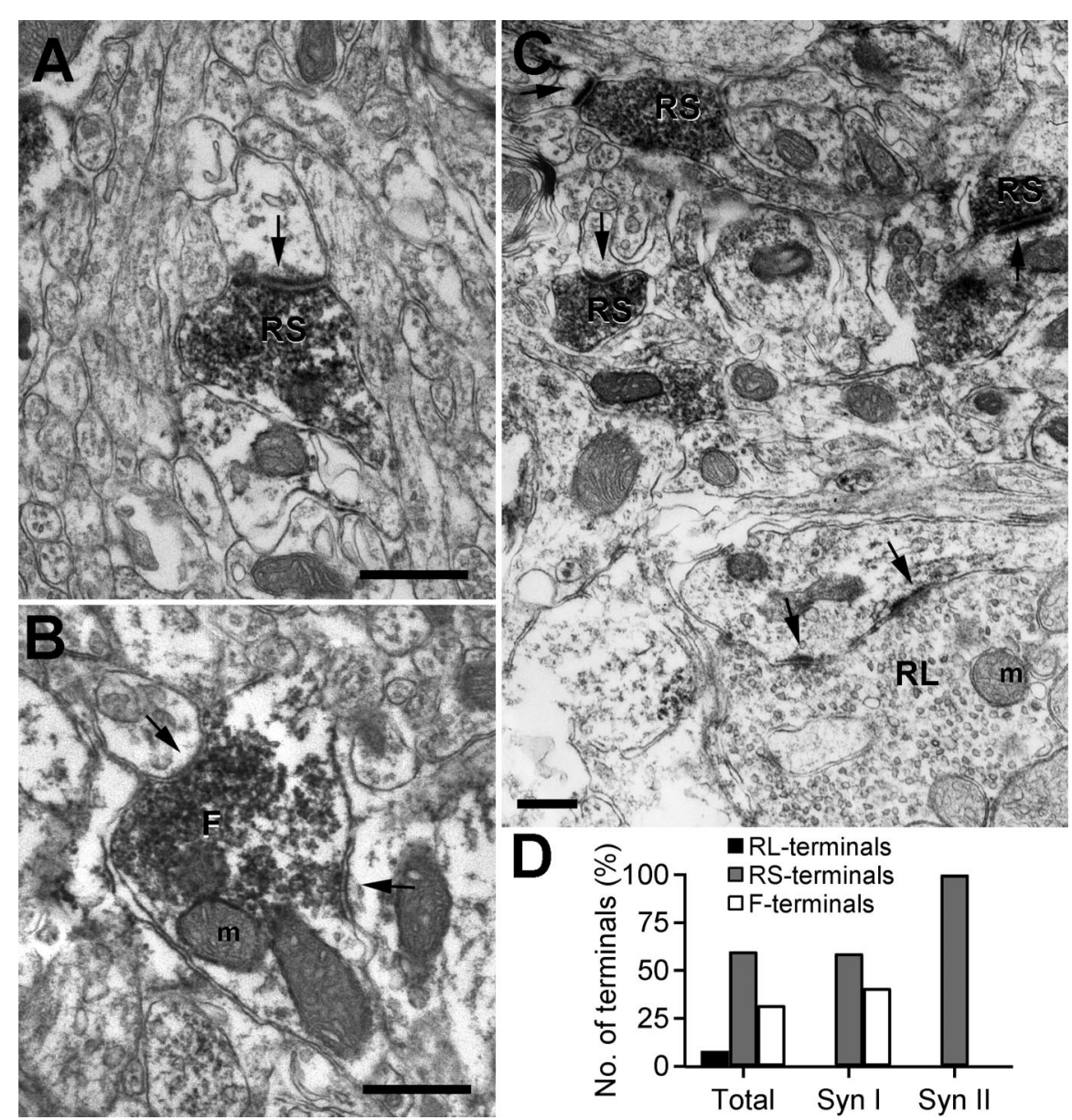

Figure 4. Synaptic terminals in LGN were differentially labeled by antibodies against synapsin I and synapsin II. $\boldsymbol{A}$, Synapsin I antibody labeling of an RS terminal forming an asymmetric synapse (arrow). B. Synapsin I antibody labeling of an F terminal forming two symmetric synapses (arrows). The F terminal contains dark mitochondria (m).C, Synapsin Il antibody labeling of three RS terminals, forming asymmetric synapses (arrows). Notice the unlabeled RL terminal, containing pale mitochondria (m), in the same field. This large terminal forms synapses (arrowheads) onto a dendrite. Scale bars, $500 \mathrm{~nm}$. D. The proportions of the RL, RS, and $\mathrm{F}$ terminals among three populations of synapses: Total, all synaptic terminals found within the same regions that were examined for the presence of labeled terminals; Syn I, all terminals labeled by antibodies against synapsin I; Syn II, all terminals labeled by antibodies against synapsin II. expression of synapsins in the two types of

terminals. For each terminal, we computed vesicle density by measuring the cross-section area, excluding mitochondrial areas, and counted the number of vesicles. We analyzed vesicle density in $87 \mathrm{RL}$ and $71 \mathrm{RS}$ terminals from five wild-type mice and $83 \mathrm{RL}$ and 91 RS terminals from five double knock-out mice. In the RL terminals, the average \pm SEM vesicle density was $104.7 \pm 3.8$ vesicles $/ \mu \mathrm{m}^{2}$ in the wild-type and $100.5 \pm 3.8$ vesicles $/ \mu \mathrm{m}^{2}$ in the double knock-out mice (Fig. 5D), and this difference was not statistically significant ( $p=0.21)$. In contrast, in the RS terminals, the vesicle density differed significantly between the double knock-out mice and the wild-type mice. In the double knock-out mice, the average \pm SEM density was $106.0 \pm 3.7$ vesicles $/ \mu \mathrm{m}^{2}$ and in the wild-type was $127.9 \pm 4.1$ vesicles $/ \mu \mathrm{m}^{2}(p=0.001)$ (Fig. 5D). An important and surprising finding expressed by these values is that the density of vesicles in the RS terminals of the double knock-out mice was not different from the density in the RL terminals of both genotypes (Fig. 5D). This finding strongly supports the conclusion that synapsin I and II are not expressed in the RL terminals.

The reduced vesicle density in the RS terminals of the double knock-out mice could reflect a change in vesicle tethering, but, alternatively, it could simply reflect a change in number of vesi- cles or in terminal area (Fig. 6A, inset). We therefore compared the RS terminals in the double knock-out and the wild-type mice with respect to these parameters. The average \pm SEM number of vesicles per RS terminal in the double knock-out was $27.2 \pm 1.7$ $(n=90)$ and in the wild-type mice was $28.2 \pm 2.2(n=70)$, and the difference between these averages was not statistically significant $(p=0.35)$. However, the average \pm SEM area of the RS terminals in the double knock-out mice $\left(0.256 \pm 0.012 \mu \mathrm{m}^{2} ; n=\right.$ 90) was larger (Fig. 6A) than the area in the wild-type mice $\left(0.219 \pm 0.012 \mu \mathrm{m}^{2} ; n=70\right)$, and this difference was statistically significant $(p=0.022)$. Accordingly, the increased area of the RS terminals in the double knock-out mice compared with the wildtype could account for the decreased vesicle density in these terminals. For the RL terminals, there was no difference between the two genotypes with respect to number of vesicles or terminal areas.

To address the question of vesicle tethering more thoroughly, we measured the distance between each vesicle and its closest neighbor in RL and RS terminals from four wild-type and four double knock-out mice. The ranges of vesicle numbers in each RS and RL terminal were 15-85 and 40-260, respectively. In RL terminals, the average \pm SEM intervesicle distance was $54.5 \pm 1.7$ 


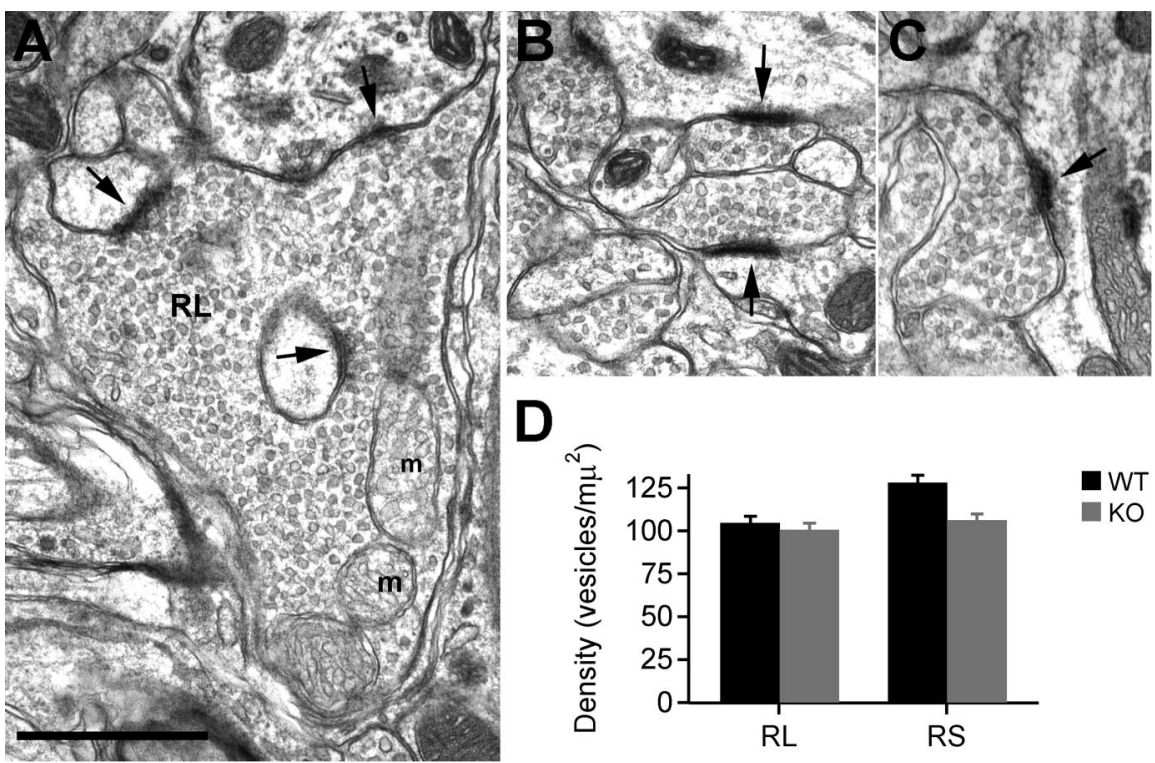

Figure 5. Synapsin I and II gene inactivation reduced the density of synaptic vesicles in terminals of corticothalamic afferents but had no effect on the density in terminals of retinothalamic afferents. $\boldsymbol{A}$, RL terminal from a double knock-out (KO) mouse, containing pale mitochondria $(\mathrm{m})$, with three synapses (arrowheads) onto geniculate dendrites. $\boldsymbol{B}$, Two RS terminals from a double knock-out mouse. C, RS terminal from a wild-type (WT) mouse. Arrows in $\boldsymbol{B}$ and $\boldsymbol{C}$ point to synapses from the postsynaptic side. Scale bar, $1 \mu \mathrm{m}$. D, Average density of vesicles in RL and RS terminals from wild-type (WT) and synapsin I and II knock-out (KO) mice. The error bars indicate SEM.

$\mathrm{nm}(n=25)$ in the wild-type and $57.5 \pm 1.4 \mathrm{~nm}(n=27)$ in the double knock-out mice, and this difference was not significantly different ( $p=0.18$ ). In the RS terminals, on the contrary, the average intervesicle distance differed significantly between the two genotypes. In the RS terminals of the wild-type mice, the average \pm SEM intervesicle distance was $46.4 \pm 1.0 \mathrm{~nm}(n=24)$ and in the double knock-out mice was $55.1 \pm 1.1 \mathrm{~nm}(n=27 ; p=$ 0.0001 ). As for vesicle density, the average intervesicle distance in the RS terminals of the double knock-out mice was similar to the average distance in the RL terminals of the double knock-out mice and the wild-type mice (Fig. $6 B$ ). The data on vesicle density and intervesicle distance strongly support the conclusion that the synapsins are present in the corticogeniculate terminals but not in the retinogeniculate terminals. Furthermore, these data are consistent with a function of synapsins in tethering of synaptic vesicles and of increasing the density within the vesicle clusters in the nerve terminals.

\section{Discussion}

Our results demonstrate a differential utilization of synapsin I and II at different types of synaptic input on LGN cells: synapsin I and II appear not to be used in the synaptic input from retina, both synapsins I and II are used in the feedback from cortex, and only synapsin I is used in GABAergic input. This conclusion is supported by several lines of evidence. First, inactivation of the synapsin I and II genes changed properties of short-term plasticity at the corticogeniculate synapses but not at the retinogeniculate synapses. Second, immunohistochemical labeling of both synapsin I and II occurred in the terminals of corticogeniculate afferents, whereas no such labeling occurred in the terminals of retinal afferents, and labeling was restricted to synapsin I in GABAergic terminals. Third, the reduced density of vesicles in synaptic terminals, demonstrated in other systems after synapsin gene inactivation (Rosahl et al., 1995; Gitler et al., 2004; Samigullin et al., 2004), occurred in the corticogeniculate but not in the retinogeniculate terminals.
One might argue that synapsin I and II have not yet reached stable expression level in the young animals we studied. Nevertheless, thalamic levels of synapsin I and II mRNA are stable from before postnatal day 7 and throughout adulthood (Zurmohle et al., 1996). We are therefore confident that there is a real difference of expression of synapsin I and II in various types of synapses in LGN. Because synapsin III (Hosaka and Südhof, 1998; Kao et al., 1998) appears to have developmental and functional characteristics that are distinct from those of synapsins I and II, particularly regarding vesicle clusters (Feng et al., 2002; Gitler et al., 2004), expression of this gene is not expected to invalidate our conclusions. A synapsin I-like protein has been demonstrated in axons of retinal ganglion cells (Baitinger and Willard, 1987). However, these axons seemed to bypass LGN and project mainly to the midbrain. The functional role of such synapsin-positive retinal axons is unknown, but their presence suggests that different functional classes of retinal ganglion cells may differ in their expression of synapsins.

In addition to the lack of synapsins, we found little short-term plasticity in retinogeniculate synapses, neither facilitation nor PTP. This could suggest that synapsins play a functional role in relation to such types of plasticity. In the corticogeniculate synapses, we observed increased paired-pulse facilitation and reduced PTP in the double knock-out mice compared with the wild type. The increased facilitation may suggest that synapsins are directly involved in the vesicle release process beside functions related to the reserve pool, because facilitation is expressed within milliseconds, whereas mobilization of vesicles from the reserve pool operates in the range of hundreds of milliseconds to seconds (Rosahl et al., 1995; Hilfiker et al., 1999). Increased facilitation is often the outcome of reduced release probability of basal synaptic transmission (Zucker and Regehr, 2002), and such reduction could possibly be caused by the synapsin gene inactivation. However, previous studies of release probability in excitatory synapses after synapsin inactivation showed no reduction in release probability; if anything, increased release probability occurred (Gitler et al., 2004; Samigullin et al., 2004). Moreover, although small effects of synapsins on the kinetics of vesicle release have been observed (Hilfiker et al., 1998; Humeau et al., 2001), there is no evidence for synapsin regulation of facilitation through functions at the release site, and the synapsins are found predominantly bound to vesicles in the reserve pool (De Camilli et al., 1983; Hirokawa et al., 1989). However, because synaptic vesicles presumably pass through a docking and a priming step before exocytosis (Zucker, 1996; Südhof, 2004) and acceleration of the priming is suggested as a mechanism of facilitation (Schoch et al., 2002), the increased facilitation could be caused by a relocation of vesicles from the reserve pool to the docked pool before the induction of facilitation. Synapsins may influence the equilibrium between the reserve pool and the docked pool by retaining vesicles in the reserve pool (Llinas et al., 1985; Hilfiker et al., 1999). Thus, synapsin inactivation may shift the equilibrium in direction of the docked pool, leading to increased potential for facili- 
A

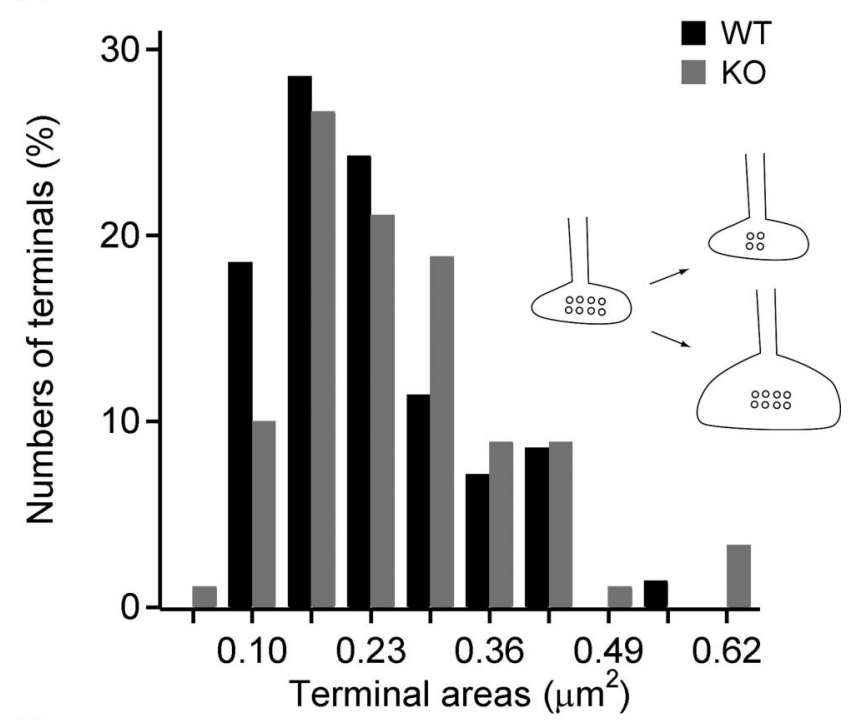

B

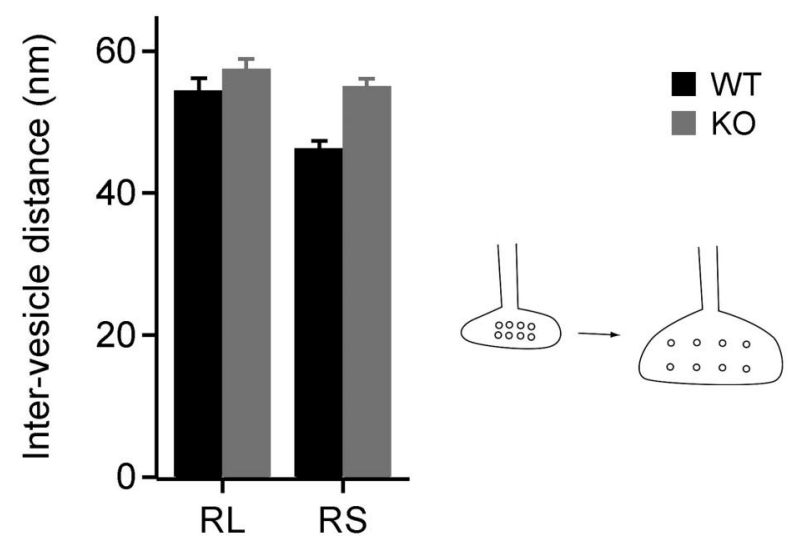

Figure 6. Terminal area and intervesicle distance at corticothalamic terminals were increased in the knock-out mice. $\boldsymbol{A}$, Frequency distribution of RS terminal area in synapsin I and II knock-out (KO) compared with wild-type (WT) mice. Increased area, rather than reduction in number of vesicles, could explain the decreased vesicle density in the knock-out mice as illustrated schematically in the inset. In each pair of bars, the black one is for wild type, and the gray one is for knock-out. Bin width, $0.065 \mu \mathrm{m}^{2}$. B , Average intervesicle distances distance in RL and RS terminals in wild-type and knock-out mice. Deletion of synapsins led to increased distance between synaptic vesicles as illustrated in the inset. The error bars are SEM.

tation because more vesicles are available for priming. Furthermore, an increased pool of docked vesicles may explain the reduced PTP. PTP is suggested to be partially caused by mobilization of vesicles from the reserve pool to the docked pool (Zucker and Regehr, 2002; Habets and Borst, 2005). Therefore, accumulation of vesicles in the docked pool attributable to synapsin I and II inactivation may limit the potential for PTPdependent increase in synaptic transmission. Regulation of vesicle trafficking may be important for synaptic plasticity, and the multiple phosphorylation sites present on synapsins could serve as targets for such mechanisms.

Several studies have demonstrated reduced numbers of vesicles after synapsin deletion in various types of synapses (Pieribone et al., 1995; Rosahl et al., 1995; Hilfiker et al., 1998; Samigullin et al., 2004). In LGN, synapsin inactivation gave no changes in number of vesicles in the RS terminals, and the reduced density appeared to be caused by increased terminal size. The reason for this difference is unclear, but differences of age could be relevant.
We studied young animals, and reductions in the number of synaptic vesicles in synapsins I and II knock-out mice may change during development. Effects of synapsin inactivation on terminal size could be synapse specific. Synapsin I and II depletion had no effect on terminal areas in hippocampus CA1 or visual cortex (Rosahl et al., 1995), whereas synapsin I inactivation gave reduced size of mossy fiber terminals in hippocampus CA3 but had no effect on terminal size of cerebellar parallel fibers (Takei et al., 1995). The mechanisms responsible for these synapse-specific effects could conceivably be related to the differences in size and structure between distinct synapses.

Previous studies have led to the suggestion that synapsin I and II are tethering synaptic vesicles into the reserve pool in the nerve terminals (Schiebler et al., 1986; De Camilli et al., 1990; Benfenati et al., 1991; Greengard et al., 1993; Pieribone et al., 1995; Rosahl et al., 1995; Gitler et al., 2004; Samigullin et al., 2004). The increased intervesicle distance we found in the corticogeniculate terminals of the synapsin I and II double knock-out mice compared with the wild-type is consistent with this hypothesis. Moreover, our analyses of intervesicle distances showed that the distance in corticogeniculate terminals of the knock-out mice was similar to the distance in the retinogeniculate terminals. This suggests that synapsin I and II have a function of increasing the density of vesicles within the reserve pool in the nerve terminals.

Our results suggest a less general distribution of synapsins in the brain than previously assumed (Hilfiker et al., 1999). Previous studies on the retina demonstrated a lack of synapsins in the terminals of photoreceptors and retinal bipolar cells (Mandell et al., 1990, 1992). These terminals make ribbon synapses, which seem to have been regarded as rare exceptions with respect to expression of synapsins (Hilfiker et al., 1999). Together with the previous findings, our data indicate that synapsins I and II are not involved in any of the three first synapses in the vertical visual pathway. All three of these synapses are drivers in the terminology of Guillery and Sherman (2002), i.e., they transmit primary afferent input to the principal cells at the next level of the pathway. In contrast, we demonstrated synapsins in terminals that transmit modulatory input to thalamocortical cells. Similarly, in the retina, synapsins are expressed in terminals mediating modulatory input (Mandell et al., 1990, 1992). These results could reflect a more general property of major pathways in the brain. Synaptic terminals mediating driver input is probably designed for powerful transmission to get the "message across." Fine regulation of vesicle release, as can be provided by the synapsins, may not be required in such synapses but could be essential in modulatory inputs from local interneurons and feedback projections, in which fine-tuning of the principal cells is the key function. The lacking expression of synapsin I and II in the retinogeniculate synapses suggest that there are differences in mechanisms of vesicle trafficking between terminals of driver inputs and modulatory inputs.

The retinal afferents in mammals mediate strong input to thalamocortical cells with high spontaneous activity and high visually driven activity [in cat, up to several hundred spikes per second (Creutzfeldt et al., 1970)]. The cortical afferents are less powerful in terms of both spontaneous and visually driven activity (Tsumoto et al., 1978). Thus, the lack of synapsins I and II in the retinal input to thalamocortical cells is in contrast to the hypothesis that the synapsins are necessary to sustain release of neurotransmitter at high rates of synaptic transmission (Greengard et al., 1993; Pieribone et al., 1995; Rosahl et al., 1995). Indeed, lack of synapsins may be a characteristic feature of synapses that operate at high rates of transmission. 


\section{References}

Baitinger C, Willard M (1987) Axonal-transport of synapsin I-like proteins in rabbit retinal ganglion-cells. J Neurosci 7:3723-3735.

Benfenati F, Valtorta F, Greengard P (1991) Computer modeling of synapsin I binding to synaptic vesicles and F-actin: implications for regulation of neurotransmitter release. Proc Natl Acad Sci USA 88:575-579.

Chen CF, Blitz DM, Regehr WG (2002) Contributions of receptor desensitization and saturation to plasticity at the retinogeniculate synapse. Neuron 33:779-788.

Chi P, Greengard P, Ryan TA (2003) Synaptic vesicle mobilization is regulated by distinct synapsin I phosphorylation pathways at different frequencies. Neuron 38:69-78.

Creutzfeldt OD, Sakmann B, Scheich H, Korn A (1970) Sensitivity distribution and spatial summation within receptive-field center of retinal oncenter ganglion cells and transfer function of retina. J Neurophysiol 33:654-671.

De Camilli P, Harris Jr SM, Huttner WB, Greengard P (1983) Synapsin I (Protein I), a nerve terminal-specific phosphoprotein. II. Its specific association with synaptic vesicles demonstrated by immunocytochemistry in agarose-embedded synaptosomes. J Cell Biol 96:1355-1373.

De Camilli P, Benfenati F, Valtorta F, Greengard P (1990) The synapsins. Annu Rev Cell Biol 6:433-460.

Erisir A, Van Horn SC, Sherman SM (1998) Distribution of synapses in the lateral geniculate nucleus of the cat: differences between laminae A and A1 and between relay cells and interneurons. J Comp Neurol 390:247-255.

Feng J, Chi P, Blanpied TA, Xu Y, Magarinos AM, Ferreira A, Takahashim RH, Kao HT, McEwen BS, Ryan TA, Augustine GJ, Greengard P (2002) Regulation of neurotransmitter release by synapsin III. J Neurosci 22:4372-4380.

Ferreira A, Kao HT, Feng J, Rapoport M, Greengard P (2000) Synapsin III: developmental expression, subcellular localization, and role in axon formation. J Neurosci 20:3736-3744.

Gitler D, Takagishi Y, Feng J, Ren Y, Rodriguiz RM, Wetsel WC, Greengard P, Augustine GJ (2004) Different presynaptic roles of synapsins at excitatory and inhibitory synapses. J Neurosci 24:11368-11380.

Granseth B, Ahlstrand E, Lindström S (2002) Paired pulse facilitation of corticogeniculate EPSCs in the dorsal lateral geniculate nucleus of the rat investigated in vitro. J Physiol (Lond) 544:477-486.

Greengard P, Valtorta F, Czernik AJ, Benfenati F (1993) Synaptic vesicle phosphoproteins and regulation of synaptic function. Science 259:780-785.

Guillery RW, Sherman SM (2002) Thalamic relay functions and their role in corticocortical communication: generalizations from the visual system. Neuron 17:163-175.

Habets RL, Borst JG (2005) Post-tetanic potentiation in the rat calyx of Held synapse. J Physiol (Lond) 564:173-187.

Hilfiker S, Schweizer FE, Kao HT, Czernik AJ, Greengard P, Augustine GJ (1998) Two sites of action for synapsin domain $\mathrm{E}$ in regulating neurotransmitter release. Nat Neurosci 1:29-35.

Hilfiker S, Pieribone VA, Czernik AJ, Kao HT, Augustine GJ, Greengard P (1999) Synapsins as regulators of neurotransmitter release. Philos Trans R Soc Lond B Biol Sci 354:269-279.

Hilfiker S, Benfenati F, Doussau F, Nairn AC, Czernik AJ, Augustine GJ, Greengard P (2005) Structural domains involved in the regulation of transmitter release by synapsins. J Neurosci 25:2658-2669.

Hirokawa N, Sobue K, Kanda K, Harada A, Yorifuji H (1989) The cytoskeletal architecture of the presynaptic terminal and molecular structure of synapsin 1. J Cell Biol 108:111-126.

Hosaka M, Südhof TC (1998) Synapsin III, a novel synapsin with an unusual regulation by $\mathrm{Ca}^{2+}$. J Biol Chem 273:13371-13374.

Hosaka M, Hammer RE, Südhof TC (1999) A phospho-switch controls the dynamic association of synapsins with synaptic vesicles. Neuron 24:377-387.

Humeau Y, Doussau F, Vitiello F, Greengard P, Benfenati F, Poulain B (2001) Synapsin controls both reserve and releasable synaptic vesicle pools during neuronal activity and short-term plasticity in Aplysia. J Neurosci 21:4195-4206.

Jovanovic JN, Sihra TS, Nairn AC, Hemmings Jr HC, Greengard P, Czernik AJ (2001) Opposing changes in phosphorylation of specific sites in synapsin I during $\mathrm{Ca}^{2+}$-dependent glutamate release in isolated nerve terminals. J Neurosci 21:7944-7953.

Kao HT, Porton B, Czernik AJ, Feng J, Yiu G, Haring M, Benfenati F, Green- gard P (1998) A third member of the synapsin gene family. Proc Natl Acad Sci USA 95:4667-4672.

Kielland A, Heggelund P (2002) AMPA and NMDA currents show different short-term depression in the dorsal lateral geniculate nucleus of the rat. J Physiol (Lond) 542:99-106.

Llinas R, McGuinness TL, Leonard CS, Sugimori M, Greengard P (1985) Intraterminal injection of synapsin I or calcium calmodulin-dependent protein kinase II alters neurotransmitter release at the squid giant synapse. Proc Natl Acad Sci USA 82:3035-3039.

Mandell JW, Townes-Anderson E, Czernik AJ, Cameron R, Greengard P, De Camilli P (1990) Synapsins in the vertebrate retina-absence from ribbon synapses and heterogeneous distribution among conventional synapses. Neuron 5:19-33.

Mandell JW, Czernik AJ, De Camilli P, Greengard P, Townes-Anderson E (1992) Differential expression of synapsin-I and synapsin-II among rat retinal synapses. J Neurosci 12:1736-1749.

Montero VM (1991) A quantitative study of synaptic contacts on interneurons and relay cells of the cat lateral geniculate nucleus. Exp Brain Res 86:257-270.

Pieribone VA, Shupliakov O, Brodin L, Hilfiker-Rothenfluh S, Czernik AJ, Greengard P (1995) Distinct pools of synaptic vesicles in neurotransmitter release. Nature 375:493-497.

Rosahl TW, Spillane D, Missler M, Herz J, Selig DK, Wolff JR, Hammer RE, Malenka RC, Südhof TC (1995) Essential functions of synapsin-I and synapsin-II in synaptic vesicle regulation. Nature 375:488-493.

Samigullin D, Bill CA, Coleman WL, Bykhovskaia M (2004) Regulation of transmitter release by synapsin II in mouse motor terminals. J Physiol (Lond) 561:149-158.

Schiebler W, Jahn R, Doucet JP, Rothlein J, Greengard P (1986) Characterization of synapsin I binding to small vesicles. J Biol Chem 262:8383-8390.

Schoch S, Castillo PE, Jo T, Mukherjee K, Geppert M, Wang Y, Schmitz F, Malenka RC, Südhof TC (2002) RIMlalfa forms a protein scaffold for regulating neurotransmitter release at the active zone. Nature 415:321-326.

Steriade M, Jones EG, McCormick DA (1997) Thalamus, Vol 1, Organization and function, pp 175-268. Amsterdam: Elsevier Science.

Südhof TC (2004) The synaptic vesicle cycle. Annu Rev Neurosci 27:509-547.

Südhof TC, Czernik AJ, Kao HT, Takei K, Johnston PA, Horiuchi A, Kanazir SD, Wagner MA, Perin MS, De Camilli P, Greengard P (1989) Synapsins: mosaics of shared and individual domains in a family of synaptic vesicle phosphoproteins. Science 245:1474-1480.

Takei Y, Harada A, Takeda S, Kobayashi K, Terada S, Noda T, Takahashi T, Hirokawa N (1995) Synapsin I deficiency results in the structural change in the presynaptic terminals in the murine nervous system. J Cell Biol 131:1789-1800.

Tsumoto T, Creutzfeldt OD, Legendy CR (1978) Functional organization of the corticofugal system from visual cortex to lateral geniculate nucleus in the cat (with an appendix on geniculo-cortical mono-synaptic connections). Exp Brain Res 32:345-364.

Turner JP, Salt TE (1998) Characterization of sensory and corticothalamic excitatory inputs to rat thalamocortical neurones in vitro. J Physiol (Lond) 510:829-843.

von Krosigk M, Monckton JE, Reiner PB, McCormick DA (1999) Dynamic properties of corticothalamic excitatory postsynaptic potentials and thalamic reticular inhibitory postsynaptic potentials in thalamocortical neurons of the guinea-pig dorsal lateral geniculate nucleus. Neuroscience 91:7-20.

Walaas SI, Greengard P (1991) Protein phosphorylation and neuronal function. Pharmacol Rev 43:299-349.

Wrobel A, Lindström S (1990) Frequency dependent corticofugal excitation of principal cells in the cat's lateral geniculate nucleus. Exp Brain Res 79:313-318.

Zucker RS (1996) Exocytosis: a molecular and physiological perspective. Neuron 17:1049-1055.

Zucker RS, Regehr WG (2002) Short-term synaptic plasticity. Annu Rev Physiol 64:355-405.

Zurmohle U, Herms J, Schlingensiepen R, Brysch W, Schlingensiepen KH (1996) Changes in the expression of synapsin I and II messenger RNA during postnatal rat brain development. Exp Brain Res 108:441-449. 